\title{
HOW CAN EVIDENCE-BASED PRACTICE CONTRIBUTE TO REDUCING HEALTH INEQUALITIES IN NSW?
}

\section{Stephen Leeder \\ Faculty of Medicine \\ University of Sydney}

Health inequalities are apparent within Australia; however, they are more starkly obvious when we compare our health with that of our Pacific and Asian neighbours. In examining how evidence-based practice can help reduce health inequalities, I begin with an example of how evidence obtained from research has been useful in dealing with a cause of massive health inequalities, a problem that consigned millions to the twilight zone of mental retardation.

Iodine deficiency is considered by the World Health Organization to be the single most common cause of preventable mental retardation and brain damage in the world. Iodine leaches from the soil in the mountains, especially when trees are cut down. Iodine deficiency has been a cause of immense health inequality, through congenital cretinism, scattered through the mountain communities of less developed nations.

The contribution of many Australians to its resolution has been a superb public health contribution. Basil Hetzel of Adelaide has had a lifelong commitment to preventive medicine and public health and is now chairman of the International Council for the Control of Iodine Deficiency Disorders. He has been involved in the prevention and control of iodine deficiency disorders since 1964, when his team showed in Papua New Guinea that brain damage due to severe iodine deficiency could be prevented by the correction of iodine deficiency before pregnancy. Iodine deficiency has been a huge public health problem in China. In Sydney, Cres Eastman of the Institute of Clinical Pathology and Medical Research at Westmead Hospital has led a team with Australian aid that over the past 20 years has worked closely with health authorities in China and the Asia Pacific region to research how to overcome this problem. The work of Cres Eastman and others in China has been a great success. The National Iodine Deficiency Disorders Elimination Program (NIDDEP) was developed in China in 1993. The principal strategy agreed upon was universal salt iodisation as well as education of the population. A review by the World Bank found that there had been excellent progress made in the efforts to eliminate iodine deficiency disorders in China through implementation of the NIDDEP. Over 90 per cent of salt is now iodised in most provinces and the national goitre rate has almost halved from 20 per cent in 1995 to 10 per cent in $1997 .{ }^{1}$ Tibet is a current area of need. Cres Eastman and colleagues are now concentrating their efforts in this area, hopefully achieving the same outstanding progress made in eliminating iodine deficiency disorders in China. ${ }^{2}$
What appeals to me greatly about this story is not only its success but also that it is a fine example of the way in which evidence from social, clinical, laboratory, and public health research has been combined with a systems and policy approach to work with communities to improve their health and reduce health inequalities.

The iodine story illustrates how, in some circumstances, health inequalities can be reduced effectively by correcting small environmental deficits. This applies to all the inequalities attributable to trace element and vitamin deficiency. It is important to note that these are preventive interventions. The interventions are effective only when applied before any disease becomes manifest.

In Australia, the opportunities for simple changes are less dramatic-universal water fluoridation, dietary supplementation when appropriate (for example, with folate and thiamine), and the provision of clean water to all indigenous communities, are among the relatively simple things we might do whose value is clear.

In Australia perhaps the most demonstrably effective reduction in health inequalities in recent years, based on evidence, has been the recent national program Immunise Australia, that addressed low immunisation completion rates among children. Although there is no evidence that I can find that suggests that the inequality due to not being immunised is related to social class, this does not diminish the difference in risk experienced by those who have been immunised and those who have not. This is a genuine health inequality. Immunise Australia, together with the advent of new technology such as immunisation against Haemophilus influenzae, has led to reductions in diseases against which immunisation is offered. This applies especially to measles.

Available statistics indicate that completed immunisation was at 75 per cent five years ago in $1997 .{ }^{3}$ With a combination of enhanced fee incentives for general practitioners to provide immunization and the passage of state legislation (in Victoria, NSW, ACT, and Tasmania) limiting access to school to children with certified completed immunisation we have seen the immunisation completion rates increase to around 86 per cent in June 2001.

Some health inequalities, attributable to differential access to effective health services, can be corrected by acting on the evidence that justifies the effective intervention. If the evidence in relation to the management of severe trauma is examined, especially in the case of head injury, the more rapid the access to high level tertiary services the better the outcome. ${ }^{4}$ No further evidence is needed to support strengthening the provision of speedy rescue services to all people with severe trauma, wherever they 
live. The question then reduces to one of cost in relation to the benefit, especially when service provision to rural and remote communities is considered. However, equity considerations may well lead to the provision of such services even though they might not make great sense in terms of efficiency.

As with all epidemiological observations, care must be exercised in interpreting associations between environmental factors and ill health and health inequalities. Thus while poverty and ill health show a close association, there is little reason for adopting a passive, utopian approach that does nothing about health inequalities on the basis that, until poverty is eradicated, illness will persist.

Interventions designed to reduce the burden of illness may enable and empower the community, otherwise depressed by its impoverished circumstances, to achieve greater economic productivity. Thus while the evidence permits us to say that there is a strong association between poverty and illness it does not permit us to say that one is completely causal of the other. Efforts to address both sets of factors are important. Thus, among indigenous children, pneumoccocal vaccination and treatment of middle ear disease may well enable children to experience far better education opportunities than if nothing specific were done about this problem. While indisputably their home environment could benefit from general environmental uplift, uplift will not be achieved if, through indolence, we do nothing to reduce the prevalence of profound deafness among the next generation.
There is an abundance, possibly a surfeit, of literature about health inequalities, much of it revolving around the notion that to improve health we must first of all improve everything else: reduce poverty, educate people, find jobs for them, house them, and give them a strong sense of social control. These explorations are nearly all based on the assumption of a linear, causal relation between every form of environmental difficulty and subsequent poor health. They appear to relieve health professionals of any obligation to act other than through political activism.

Utopian notions of waiting for the revolution are the emperor's new clothes. There is ample evidence that a few effective interventions can be mounted to improve health and reduce inequalities right now. If I had a choice, that's where I'd put my health dollar first.

\section{REFERENCES}

1. Eastman C. Iodine deficiency disorders in China-overcoming a massive public health problem. Today's Life Science November-December 1999.

2. Eastman C, Watkins W, Ashraf Ul-Alam AKF. Feasibility Study on Iodine Deficiency Disorders Elimination Project in Tibet. Geneva: Report to World Health Organization, June 1999.

3. Department of Health and Aged Care. Vaccine preventable diseases and vaccination coverage in Australia, 1993-1998Supplement. Canberra: Department of Health and Aged Care, June 2000.

4. Stone JL, Lowe RJ, Jonasson O, Baker RJ, Barrett J, Oldershaw JB, Crowell RM, Stien RJ. Acute subdural haematoma: direct admission to a trauma center yields improved results. J Trauma 1986; 26: 445-450. 照 